\title{
Fenômenos como mediadores do processo educativo em Ciências da Natureza e Matemática na Educação do Campo
}

\author{
Marcelo Gules Borges ${ }^{1}$, Juliano Espezim Soares Faria ${ }^{2}$, Elizandro Maurício Brick ${ }^{3}$ \\ ${ }^{1}$ Universidade Federal de Santa Catarina - UFSC. Departamento de Educação do Campo. Centro de Ciências da \\ Educação. Campus Reitor João David Ferreira Lima s/n. Trindade. Florianópolis - SC. Brasil. \\ marcelo.borges@ufsc.br. ${ }^{2}$ Universidade Federal de Santa Catarina - UFSC. ${ }^{3}$ Universidade Federal de Santa \\ Catarina - UFSC.
}

RESUMO. A partir do estudo dos fenômenos apresentamos neste artigo as possibilidades de seus usos nas licenciaturas em Educação do Campo como categoria conceitual que articula Ciências da Natureza e Matemática à materialidade e à realidade. Tendo como universo empírico uma prática pedagógica realizada na Licenciatura em Educação do Campo da Universidade Federal de Santa Catarina analisamos as estratégias tomadas e caminhos seguidos na elaboração de estudos de conhecimentos específicos das Ciências da Natureza e Matemática na delimitação da dimensão natural de fenômenos socialmente relevantes no contexto de origem dos licenciandos. Com base na experiência descrita e sob inspiração da fenomenologia discutimos o papel e a potencialidade dos fenômenos como mediadores e organizadores dos conhecimentos coproduzidos com o mundo.

Palavras-chave: Fenômenos, Ensino de Ciências da Natureza e Matemática, Educação do Campo. 


\title{
Phenomena as mediators in science education and mathematics in the Educação do Campo (Education for and by the countryside)
}

\begin{abstract}
From the study of the phenomena, we present in this article the possibilities of its uses in the Educação do Campo (Education for and by the countryside) as a concept that articulates Natural Sciences and Mathematics, materiality and, reality. From an experience in the Educação do Campo course at the Federal University of Santa Catarina, we analyze the strategies adopted and the paths followed in the studies of concepts from the natural sciences and mathematics in the delimitation of the natural dimension of phenomena in the life context of the undergraduate's students. Based on this experience and inspired by phenomenology, we discuss the role and potential of phenomena as mediator and organizer of the knowledge coproduced with the world.
\end{abstract}

Keywords: Phenomena, Science Education and Mathematics, Rural Education. 


\section{Fenómenos como mediadores del proceso educativo en Ciencias de la Naturaleza y Matemáticas en la Educação do Campo (educación rural)}

RESUMEN. A partir del estudio de los fenómenos presentamos en este artículo las posibilidades de sus usos en las licenciaturas en Educación del Campo como categoría conceptual que articula Ciencias de la Naturaleza y Matemática a la materialidad y la realidad. Desde la práctica pedagógica realizada en la Licenciatura en Educación del Campo de la Universidad Federal de Santa Catarina analizamos las estrategias tomadas y caminos seguidos en la elaboración de estudios de conocimientos específicos de las Ciencias de la Naturaleza y Matemáticas en la delimitación de la dimensión natural de fenómenos socialmente relevantes en el ámbito del contexto de origen de los licenciandos. Con base en la experiencia descrita y bajo inspiración de la fenomenología discutimos el papel y la potencialidad de los fenómenos como mediadores $\mathrm{y}$ organizadores de los conocimientos coproducidos con el mundo.

Palabras clave: Fenómenos, Enseñanza de Ciencias Naturales y Matemáticas, Educación Rural. 


\section{Introdução}

$\mathrm{O}$ que temos aprendido quando organizamos nossos estudos e docência no contexto do Ensino das Ciências da Natureza e Matemática na Educação do Campo a partir de fenômenos do mundo material? Tal pergunta mobilizou nossas reflexões diante da experiência educativa realizada no âmbito da Licenciatura em Educação do Campo da Universidade Federal de Santa Catarina (UFSC) em 2015, na disciplina denominada Fundamentos das Ciências da Natureza e Matemática na Educação do Campo II, oferecida na $4^{\mathrm{a}}$ fase deste curso.

Considerando o aparato conceitual dos componentes curriculares Biologia, Física e Matemática e os princípios da Educação do Campo, propusemos organizar as atividades da disciplina a partir da delimitação e estudo dos fenômenos com relevância social do ponto de vista da população local. Depois de iniciar esse movimento é que então realizamos desdobramentos a partir de conceitos específicos da Biologia, da Física e da Matemática para a compreensão dos fenômenos na/e da realidade.

Este artigo tem por objetivo analisar uma prática pedagógica na Licenciatura Educação do Campo a fim de discutir e destacar os modos pelos quais os fenômenos podem ser potentes para o Ensino das Ciências da Natureza e Matemática. Do ponto de vista metodológico trata-se de uma investigação qualitativa, sendo os principais investigadores nativos do contexto em questão, o que propiciou o uso da "autoobservação" (Gutiérrez \& Delgado, 1998), na qual os próprios autores fazem parte do sistema a ser analisado. Desse modo, foram realizadas observações-participante e anotações em diário de campo como fonte primária, bem como buscas de literatura (fontes secundárias) demandadas pelo movimento de construção do trabalho.

O texto está organizado em três partes. Primeiramente, apresentamos alguns aspectos teóricos acerca do entendimento da noção de fenômeno e seus usos na literatura educacional, situando o leitor sobre o lugar de fala assumido pelos autores. $\mathrm{Na}$ segunda, descrevemos o processo educativo, tratando de detalhes da componente curricular, da forma como identificamos e selecionamos fenômenos e de como mobilizamos conceitos específicos das Ciências da Natureza e Matemática para compreendê-los. $\mathrm{Na}$ terceira, tecemos algumas considerações sobre a experiência, apontando as potencialidades, bem como, os limites que no servem de horizonte para práticas pedagógicas futuras. 
Fenômenos no Ensino de Ciências da Natureza e Matemática na Educação do Campo

A proposta de uma organização de estudos e docência baseada em fenômenos no contexto desta experiência partiu de necessidades pontuais relativas à nossa atuação na Licenciatura em Educação do Campo da UFSC. De um lado, está o desafio constante de atuar por área de conhecimento, realizando movimentos interdisciplinares, de um modo que não fez parte de nossa formação acadêmica disciplinar. De outro, a característica inerente à componente curricular na qual atuamos naquela oportunidade, Fundamentos das Ciências da Natureza e Matemática II, oferecida na $4^{\mathrm{a}}$ fase do curso. No currículo desta licenciatura, é a partir da $3^{\mathrm{a}}$ fase (até a última) que os estudantes cursam semestralmente componentes curriculares desta natureza.

Seu princípio organizador, conforme Projeto Político Pedagógico (UFSC, 2009), é de que os estudantes possam experienciar o movimento de diálogo entre as disciplinas na análise das diferentes dimensões da realidade. Ao mesmo tempo em que ela tem o objetivo de preparar os estudantes do ponto de vista conceitual desde as diferentes disciplinas da área de conhecimento das Ciências da Natureza e Matemática, é a partir dela que se ensaiam movimentos multi/interdisciplinares de organização do conhecimento.

Rotineiramente, afirmamos que esta componente curricular é uma referência para a própria atuação futura dos estudantes nas escolas do campo, seja pela sua natureza multidisciplinar seja por exigir movimentos de diálogo entre docentes e colegas estudantes na definição e organização dos estudos.

Colocar os fenômenos na centralidade deste processo, em nossa atuação, isto é, organizar a disciplina com base em estudos dos conhecimentos específicos da área em direção à compreensão dos fenômenos, garantiria, de partida, nossa atenção ao mundo natural, o que em nosso entendimento potencializa a aprendizagem dos conhecimentos das Ciências da Natureza e Matemática nas licenciaturas em Educação do Campo.

Ainda, a clareza do pressuposto inicial para esta escolha dos fenômenos como organizador dos estudos nas disciplinas de Fundamentos das Ciências da Natureza e Matemática remete ao tempo e carga-horária dedicada no curso para as componentes curriculares do núcleo específico de conhecimento objeto de ensino dos educadores que se está formando. Nesse sentido, uma abordagem baseada em fenômenos nos respectivos territórios tem a função de não somente articular a produção de conhecimentos e as 
realidades locais, mas, especialmente, focalizar a atenção dos estudantes e educadores ao desafio de mobilizar as produções advindas da Biologia, da Física e da Matemática. Ou seja, as discussões sociais e ambientais associadas aos fenômenos tem sua tematização prevista para um plano em outra escala, isto é, os fenômenos foram ponto de partida para os aprofundamentos conceituais e não como exemplos genéricos, sem vínculo significativo algum com a realidade dos estudantes. As discussões supramencionadas faziam parte da componente curricular em curso, cujo foco consistia no estudo e apropriação das redes conceituais de interpretação dos fenômenos desde as diferentes áreas.

Parte de nossa premissa teórica considera que não bastariam apenas os conhecimentos dos elementos biofísicos, mesmo considerando os diferentes campos disciplinares que o compõem, para garantir a compreensão dos fenômenos e suas relações nos diferentes sistemas biofísicos e socioeconômicos das relações humanas nos diferentes territórios (Francis et al., 2013). Deste modo, cabe ressaltar que o estabelecimento de relações com a realidade, com a vida cotidiana dos sujeitos, não estava determinada inicialmente como movimento da componente curricular, já que este era prérequisito para seleção dos fenômenos.

Assim, podemos dizer que a noção de fenômeno que aqui utilizamos advém de um senso prático (Bourdieu, 2009) do ponto de vista da prática docente. Ou seja, os fenômenos permitem uma busca incessante em organizar e produzir situações de aprendizagem que priorizem os conhecimentos das Ciências da Natureza e da Matemática, como forma de potencializar diferentes percepções da realidade imediata, da vida das populações, dos docentes e dos próprios estudantes em seus territórios. A opção pelo uso dos fenômenos não deixa de ser uma busca prática de resposta a estas questões, já que os fenômenos são a mediação material e discursiva entre mundo e conceitos.

\section{Entre mundo e conceitos há fenômenos}

Temas, conceitos e fenômenos são construtos humanos. Poderíamos dizer que, desde uma noção construtivista e representacional são coproduzidos no âmbito da linguagem. Temas e conceitos são textos das Ciências (no sentido hermenêutico) sobre a natureza. Da mesma forma que a própria ideia de natureza é um texto sobre seu próprio referente. Fenômenos também, contudo carregados de materialidade (física e social). Os fenômenos são mediadores do texto da 
ciência e da textura do mundo. De outro modo, são a mediação material e discursiva entre mundo e conceitos.

Longe de realizarmos uma digressão conceitual a respeito dos fenômenos, é na tradição fenomenológica da filosofia continental (Husserl e Merleau-Ponty) que encontramos sentido (prático) para aquilo que entendemos ser o argumento que fundamenta este tipo de abordagem para o ensino por área de conhecimento.

Desde uma premissa fenomenológica os fenômenos estão ancorados no mundo pré-objetivo sempre em contextos (Merleau-Ponty, 2014). Aprender, neste sentido, é considerar que estamos imersos em um mundo material carregado de contextos culturais. Assim, uma abordagem fenomenológica balancearia a predominância de explicações conceituais abstratas conectando-as com os modos de estar e agir no mundo, como base para uma compreensão da vida e da realidade. Nesta abordagem o ensino de Ciências da Natureza e Matemática é caracterizado pelo uso de um contexto específico como ponto de partida para delimitação dos fenômenos, bem como, para desenvolvimento de compreensão das ideias científicas.

A aprendizagem baseada em contexto é semelhante à abordagem fenomenológica, uma vez que ambos visam superar o fosso entre o mundo da vida e os conceitos científicos. No entanto, eles diferem substancialmente em um ponto, pois os professores de ciência com inspiração fenomenológica tendem a considerar os fenômenos do mundo da vida como a própria base e não meras ilustrações do conhecimento científico. Assim, na fenomenologia, não se busca o contexto apropriado para promover a compreensão dos alunos sobre os conteúdos específicos da ciência, mas mais do que isso procura-se desenvolver a capacidade dos alunos em desvelar os fenômenos do mundo da vida como uma entrada na compreensão da natureza (Ostergaard et al., 2008, p. 98).

A título de exemplo, cabe aqui mencionar a experiência conduzida por Francis et. al. (2013). Nesta prática os autores retratam o papel da fenomenologia naquilo que chamam de uma "educação agroecológica”. Sob inspiração da aprendizagem baseada em fenômenos (phenomenon-based learning) no ensino de ciências da natureza os autores partem da premissa de que comparado com estratégias práticas que promovem uma aprendizagem holística e ampla, o movimento de especialização na academia a partir das disciplinas nas recentes décadas tem conduzido a uma formação especialista cada vez mais restrita aos seus campos. Em síntese, a atenção dada à teoria tem sido distante da realidade de vida das pessoas.

Ainda que o estudo se refira à formação em Agroecologia (o que 
inclusive é projeto político-pedagógico do movimento da Educação do Campo) os autores defendem que o foco nos elementos dos sistemas não é suficiente para compreensão da realidade, ou seja, é preciso uma compreensão dos sistemas como um todo, o qual englobaria compreender os fenômenos desde um ponto de vista biofísico, econômico, social e cultural: desde os diferentes métodos das Ciências Humanas, da Natureza e da Matemática.

Os fenômenos com os quais operamos aqui são tentativas de um esforço teórico de apreender com o mundo material e os discursos das ciências a natureza em sua noção mais física possível. A radicalidade da forma como tratamos os fenômenos não pode ser descolada do cotidiano da vida dos estudantes. Como afirmamos anteriormente, trata-se de um desvio intencional, não excludente das discussões contextuais.

É exatamente na fisicalidade do mundo (da natureza) e seus processos de produção e de transformação que fenômenos são coproduzidos pelos discursos da ciência. O que propomos fazer, em certo sentido, é operar com o plano material dos conceitos no sentido de potencializarmos as aprendizagens das Ciências na Educação do Campo.
Nossa inspiração é em parte do movimento contemporâneo denominado virada ontológica ${ }^{\mathrm{i}}$, o qual inclui pesquisadores que buscam o esforço de escapar dos dualismos do mundo moderno, dentre os quais matéria-linguagem, pois fenômenos são constitutivos da realidade e esta é composta não de coisas por elas mesmas ou coisas "atrás" dos fenômenos, mas por coisas nos fenômenos (Barad, 2007; Higgins, 2016).

Por fim, os fenômenos, antes de qualquer coisa, são necessariamente materiais e físicos. No contexto desta experiência que apresentamos seus critérios de escolha remetem a um posicionamento político claro e objetivo. Trata-se de fenômenos que importam na vida cotidiana das populações do campo. Neste sentido, é de outra materialidade que também queremos falar, aquela vinculada e vivida desde o ponto de vista social, econômico, cultural e ambiental nos territórios. Essa é parte da premissa $a$ priori que identifica o modo pelo qual estamos tratando os fenômenos, e de forma mais específica o que chamamos de fenômenos da natureza (aqueles considerados objeto de conhecimento pelas Ciências da Natureza). Ou seja, compreendemos que não há fenômenos que não sejam banhados de realidade. É o que passamos a mostrar a seguir. 


\section{A prática pedagógica}

A prática educativa docente que inspirou a análise ocorreu na quarta fase do referido curso, na componente curricular intitulada Fundamentos das Ciências da Natureza e Matemática na Educação do Campo II. Esta componente curricular tem caráter de aprofundar conhecimentos específicos das áreas das Ciências da Natureza e Matemática e foi ministrada por docentes da área de Ensino de Física, Ensino de Matemática e Ensino de Biologia. Esta componente foi cursada por estudantes da região do Vale Contestado, especificamente dos municípios de Curitibanos, Frei Rogério, Fraiburgo e Timbó Grande, e São Pedro de Alcântara, na região da Grande Florianópolis em Santa Catarina.

Diante da ementa ${ }^{\mathrm{ii}}$ da referida componente curricular e ao considerar nossa prévia relação acadêmica, na qual desenvolvemos juntos trabalhos ligados a outras turmas do curso, as ideias que surgiram em nossos planejamentos foram criando espaço para esta experiência que visava o seguinte movimento: 1) definir em conjunto com os estudantes fenômenos com ocorrência e relevância nos seus respectivos territórios; 2) delimitar a dimensão natural dos fenômenos escolhidos; 3) estudar os conceitos da
Biologia, da Física e da Matemática necessários para a compreensão dos fenômenos; 4) bem como, a mobilização dos mesmos para estudar os fenômenos e seus impactos nos desdobramentos sociais do local. Este arranjo nos fez decidir que o plano de ensino só poderia ser socializado a partir do momento em que estivessem delimitados os objetivos ligados aos fenômenos que seriam elencados e selecionados para estudo.

Baseado no diagnóstico de realidade (produto final do primeiro ano do curso) e demais registros de atividades dos Tempos-Comunidade (TC) dos semestres anteriores $^{\text {iii }}$, a primeira atividade realizada consistiu em identificar fenômenos ligados à realidade local na qual os estudantes realizavam o TC. Feita a primeira seleção de fenômenos, com o intuito de ampliar o olhar sobre os itens da seleção, os estudantes realizaram uma pesquisa de fontes secundárias sobre os territórios/fenômenos no acervo da biblioteca universitária, no google acadêmico, nos materiais utilizados e produzidos em outros momentos do curso e em outros mecanismos de busca. $\mathrm{Na}$ tabela que segue, a primeira coluna é constituída pelos fenômenos elencados pelos estudantes e a segunda, as referências pesquisadas: 
Borges, M. G., Faria, J. E. S., \& Brick, E. M. (2017). Fenômenos como mediadores do processo educativo em Ciências da Natureza e Matemática na Educação do Campo...

Tabela1: Fenômenos localizados preliminarmente pelos estudantes e as respectivas referências encontradas.

\begin{tabular}{|c|c|}
\hline FENÔMENOS & REFERÊNCIAS LOCALIZADAS \\
\hline $\begin{array}{l}\text { 1. Avanço Industrial } \\
\text { 2. Precarização do Campo/Escola } \\
\text { 3. Saída das pessoas do campo } \\
\text { 3.1. Predomínio da indústria madeireira } \\
\text { 3.2. Produção de pasta mecânica } \\
\text { 3.3. Produção de celulose } \\
\text { 3.4. Desemprego } \\
\text { 3.5. Vilas em torno das empresas } \\
\text { 3.6. Construção de PCHs } \\
\text { 3.7. Precarização das áreas periféricas } \\
\text { 3.8. Jovens não projetam o futuro na região } \\
\text { (falta de perspectiva) } \\
\text { 3.9. Evasão dos jovens } \\
\text { 3.10. Invisibilidade dos movimentos sociais } \\
\text { 3.11. Catástrofes climáticas: granizo, geada e } \\
\text { tornado } \\
\text { 3.12. Crescimento da agricultura familiar }\end{array}$ & $\begin{array}{l}\text { 1. Fragmentação florestal e atividade madeireira: um estudo } \\
\text { da ecologia da paisagem em Curitibanos, Santa Catarina. } \\
\text { (2007). } \\
\text { http://repositorio.ufsc.br/xmlui/handle/123456789/90263 } \\
\text { 2. Educação de jovens e adultos do campo: um estudo sobre o } \\
\text { PRONERA em Santa Catarina (2007) } \\
\text { Link: } \\
\text { http://repositorio.ufsc.br/xmlui/handle/123456789/90295 } \\
\text { 3. Educação do Campo em Curitibanos, Santa Catarina: } \\
\text { Reflexões sobre a Criação e Paralisação das Escolas Isoladas - } \\
\text { Cristina Ehrhardt Maria Agustini Moraes Ehrhardt } \\
\text { Link: } \\
\text { http://editora.unoesc.edu.br/index.php/coloquiointernacional/a } \\
\text { rticle/view/1249 }\end{array}$ \\
\hline $\begin{array}{l}\text { 1. Não há coleta de embalagens de } \\
\text { agrotóxicos } \\
\text { 2. Estradas sem devida pavimentação } \\
\text { 3. Precariedade do ônibus escolar em } \\
\text { horários, utilizado pela população em geral } \\
\text { 4. Escassez de empregos } \\
\text { 5. Não há instituição de Ensino Superior } \\
\text { 6. Não há Hospital e Hotel } \\
\text { 7. Não há área de lazer } \\
\text { 8. Alcoolismo, Estupro, roubos } \\
\text { 9. Questão: A escola é ou não do campo? } \\
\text { 10. Alimentação escolar apenas para cumprir } \\
\text { a lei } \\
\text { 11. Creches provisórias } \\
\text { 12. Decadência Cultural } \\
\text { 13. Pouco incentivo aos pequenos } \\
\text { agricultores, a agricultura em geral } \\
\text { 14. Industrialização (avanços) } \\
\text { 15. Desmatamento, poluição e lixo } \\
\text { 16. Uso indevido de agrotóxicos } \\
\text { 17. Êxodo rural } \\
\text { 18. Evasão de jovens do município } \\
\text { 19. Presença de Ensino Médio Inovador }\end{array}$ & $\begin{array}{l}\text { 1. Santa Catarina em Números. } \\
\text { http://www.sebrae-sc.com.br/scemnumero/arquivo/Frei- } \\
\text { Rogerio.pdf } \\
\text { Autor: Cândido, Marcondes da Silva. II. Ferreira, Cláudio. III. } \\
\text { Grapeggia, Mariana. IV. Silva, Jackson André da. V. Três, } \\
\text { Douglas Luiz. }\end{array}$ \\
\hline $\begin{array}{l}\text { 1. Produção de maçã } \\
\text { 2. Exploração floresta nativa (história } \\
\text { ambiental) } \\
\text { 3. Produção diversificada }\end{array}$ & $\begin{array}{l}\text { 1. MOHR, M. F.; RIBAS, C. E. D. Formação de Jovens na } \\
\text { Escola } 25 \text { de Maio - Entre os limites e as possibilidades da } \\
\text { construção da agroecologia. SIFEDOC Regional, Santa Maria, } \\
2014 \text { Disponível }\end{array}$ \\
\hline
\end{tabular}

\begin{tabular}{|l|l|l|l|l|l|l|l|}
\hline Rev. Bras. Educ. Camp. & Tocantinópolis & v. 2 & n. 3 & p. $965-990$ & jul./dez. & 2017 & ISSN: 2525-4863 \\
\hline
\end{tabular}


Borges, M. G., Faria, J. E. S., \& Brick, E. M. (2017). Fenômenos como mediadores do processo educativo em Ciências da Natureza e Matemática na Educação do Campo...

\begin{tabular}{|c|c|}
\hline $\begin{array}{l}\text { 4. Falta de atividade para os jovens } \\
\text { 5. Tecnologia } \\
\text { 6. Indústrias } \\
\text { 7. Escola do campo } \\
\text { 8. Clima }\end{array}$ & $\begin{array}{l}\text { <http://coral.ufsm.br/sifedocregional/images/Anais/Eixo } \% 200 \\
\text { 3/Matheus\%20Fernando\%20Mohr.pdf>. } \\
\text { 2. Fenômeno: Exploração significativa das florestas } \\
\text { BRUNI, S. Certificação de Manejo Florestal de florestas } \\
\text { plantadas de Pinus na unidade Campo Alto, município de } \\
\text { Água Doce - SC. (Relatório de Auditoria). 2007. Disponível } \\
\text { em: < https://www.tuv- } \\
\text { nord.com/data/content_data/tng_br_pt/relatorio-de-auditoria- } \\
\text { trombini.pdf >. }\end{array}$ \\
\hline $\begin{array}{l}\text { 1. Êxodo rural } \\
\text { 2. Escola pública típica } \\
\text { 3. Plantações de Pinus (Pinus spp.) } \\
\text { 4. Pedofilia } \\
\text { 5. Falta de lazer } \\
\text { 6. Infra-estrutura }\end{array}$ & \\
\hline $\begin{array}{l}\text { 1. Lixão céu aberto } \\
\text { 2. Falta de saneamento } \\
\text { 3. Êxodo rural } \\
\text { 4. Chuva impede acesso à escola } \\
\text { 5. Acesso precário à informática } \\
\text { 6. Não há biblioteca, escolas e espaço } \\
\text { cultural } \\
\text { 7. Evasão dos alunos } \\
\text { 8. Jovens saem para trabalhar em empresas } \\
\text { de Pinus (Bonet, Lavra-Sul) }\end{array}$ & $\begin{array}{l}\text { 1. Reportagens sobre o lixo em Timbó Grande: } \\
\text { http://jornalinforme.com.br/cacador/index.php/editorias/cotidi } \\
\text { ano/item/1987-moradores-de-timbo-grande-sofrem-com- } \\
\underline{\text { infraestrutura-precaria-na-administracao-do-lixo-coletado }} \\
\underline{\text { http://noticiahoje.net/prefeitura-de-timbo-grande-explica-lixo- }} \\
\underline{\text { acumulado/ }}\end{array}$ \\
\hline $\begin{array}{l}\text { 1. Aumento mata ciliar } \\
\text { 2. Controle mosquito (moscas) por BTI } \\
\text { (pulverização) } \\
\text { 3. Relatos de abuso sexual crianças } \\
\text { 4. Destruição do solo por agrotóxicos } \\
\text { 5. Contaminação do rio (agrotóxico e } \\
\text { cemitério) } \\
\text { 6. Diminuição de agricultores e aumento de } \\
\text { sitiantes (diálogo entre culturas - } \\
\text { conservadorismo cultura alemã: língua, } \\
\text { arquitetura, organização) } \\
\text { 7. Aumento da população carcerária } \\
\text { 8. Perda na produção de alimentos } \\
\text { 9. Destruição materiais didáticos } \\
\text { 10. Falta de atividades para jovens (espaços } \\
\text { culturais/esportivos) }\end{array}$ & 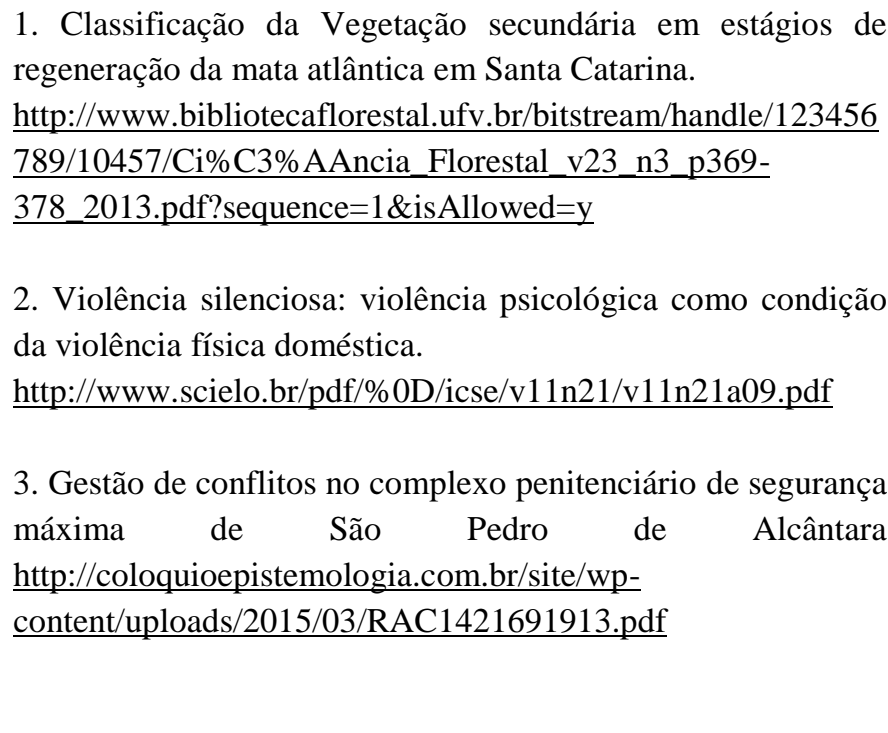 \\
\hline $\begin{array}{l}\text { 1. Avanço industrial } \\
\text { 2. Controle de moscas por pulverização } \\
\text { 3. Diálogo entre saberes (novos moradores) } \\
\text { 4. Não há tratamento de esgoto } \\
\text { 5. Intolerância }\end{array}$ & $\begin{array}{l}\text { 1. Sucessão florestal secundária no município de São Pedro de } \\
\text { Alcântara, litoral de Santa Catarina: estrutura e diversidade } \\
\text { http://cascavel.cpd.ufsm.br/revistas/ojs- } \\
\underline{2.2 .2 / \text { index.php/cienciaflorestal/article/view/1778 }}\end{array}$ \\
\hline
\end{tabular}

\begin{tabular}{|l|l|l|l|l|l|l|l|}
\hline Rev. Bras. Educ. Camp. & Tocantinópolis & v. 2 & n. 3 & p. 965-990 & jul./dez. & 2017 & ISSN: 2525-4863 \\
\hline
\end{tabular}


6. Cultura tradicional da escola

7. Falta de espaços culturais esportivos

8. Conteúdos das Ciências da Natureza não conversam com a realidade

9. Conservadorismo da cultura alemã (língua, arquitetura, organização)

10. Controle celulares na escola

11. Alimentação escolar $100 \%$

industrializada

12. Religião católica

13. Não Feiras de Ciências

14. Migrações
2. São Pedro de Alcântara: paisagem e rupturas "https://periodicos.ufsc.br/index.php/geosul/article/view/1374 6" Maria Dolores Buss, Luis Fernando Scheibe, Sandra Maria de Arruda Furtado

\section{Fonte: Pesquisa dos autores.}

De posse dos resultados desta pesquisa inicial, passamos à etapa de seleção de alguns dos fenômenos elencados, de tal forma que pudéssemos passar ao estudo de conhecimentos específicos das Ciências da Natureza e Matemática o qual permitisse uma compreensão mais ampla daqueles fenômenos. Assim, a explicitação, posterior discussão e deliberação coletiva sobre os critérios de escolha do fenômeno a ser estudado pelos grupos, foram os seguintes:

1. Precisa estar relacionada à escola (cultura escolar);

2. Precisa estar presente na comunidade local;

3. Precisa estar situado na região/localidade;

4. Deve considerar o PPP da escola;

5. Precisa estar relacionado à saúde, à alimentação e à agricultura (vida do agricultor);
6. Precisar estar relacionado à alimentação e à agricultura;

7. Precisa estar relacionado com problemas ambientais;

8. Deve estar relacionado à dinâmica da vida social e familiar (relevância social para as pessoas do local);

9. Deve ser passível de análise pela área de atuação/formação do curso;

10. Deve estar relacionado aos princípios da Educação do Campo e aos sujeitos do campo (povos da terra, das águas e das florestas);

11. Deve estar contemplado às propostas curriculares.

$\mathrm{Na}$ socialização de todos esses pontos expostos pelos estudantes, cada um explicou seus critérios de escolha, o que gerou uma discussão permitindo o estabelecimento de consenso e síntese do que estudantes e docentes julgavam como mais importante considerar naquela situação, chegando a três critérios finais e 
um objetivo geral (Tabela 2). A partir desses elementos foi possível encaminhar a atividade seguinte, que consistiu em cada grupo escolher um dos fenômenos segundo os critérios e sistematizar de forma escrita uma justificativa que seria apresentada para o coletivo avaliar se atendia ou não aos critérios sintetizados.

Tabela 2: Objetivo e critérios para escolha do fenômeno decidido coletivamente após discussão coletiva.

\begin{tabular}{|c|c|}
\hline Objetivo do estudo & $\begin{array}{l}\text { Analisar o fenômeno escolhido a partir da área específica de formação do curso } \\
\text { (Ciências da Natureza e Matemática) }\end{array}$ \\
\hline \multirow{3}{*}{$\begin{array}{l}\text { Critérios para escolha } \\
\text { do fenômeno: }\end{array}$} & Esteja situado na região/localidade de realização TC \\
\hline & $\begin{array}{l}\text { 2. Esteja relacionado com a dinâmica da vida social e familiar (relevância } \\
\text { social e ambiental para as pessoas do local) }\end{array}$ \\
\hline & Esteja relacionado aos princípios do Movimento da Educação do Campo \\
\hline
\end{tabular}

Fonte: Pesquisa dos autores.

Com base neste objetivo e critérios, os fenômenos escolhidos por cada grupo a partir de uma discussão no grande grupo foram os seguintes: "Ocorrência de geadas no Vale do Contestado, SC", "Substituição da Mata Nativa por vastas plantações de Pinus (Pinus sp.) em Timbó Grande, SC”, "Reconstituição da Mata Ciliar em São Pedro de Alcântara, SC".

Findada essa etapa, foi possível vislumbrar os objetivos que passaram a compor o plano de ensino da referida componente curricular. Um deles se constituiu em identificar fenômenos a partir dos registros (dados primários) dos TCs, da produção técnico-científica sobre os contextos dos territórios onde são realizados os TCs e estabelecer critérios para seleção daqueles que seriam estudados. Outro objetivo consistiu em abordar conceitos estruturantes de Ciências da Natureza e Matemática a partir dos fenômenos da natureza delimitados. Também buscamos identificar, problematizar e dialogar a partir dos saberes prévios dos estudantes a respeito dos fenômenos, além de introduzir conceitos das diferentes disciplinas como chave de leitura de aspectos dos fenômenos problematizando as narrativas sobre Mudanças

Climáticas, Biodiversidade e Água no contexto contemporâneo da Sustentabilidade e da Educação do Campo.

Tais objetivos foram desdobrados em três unidades de estudos. A primeira, 
transcorrida em três encontros de quatro horas-aula correspondente à descrição feita até aqui. As outras duas unidades da componente curricular foram desenvolvidas de forma paralelas e alternadas. A unidade 2 teve um total de nove encontros, nos quais a atividade principal foi a de estudar os fenômenos escolhidos junto com os professores, os quais nesses encontros assumiram um papel mais de orientadores-professores, indicando referências, estudando junto com os estudantes individualmente e em grupo às referências indicadas e localizadas. A Unidade 3 foi composta por 9 encontros, nos quais cada um dos três professores ministraram aulas com base no conhecimento de suas áreas específicas de graduação relacionado aos fenômenos estudados conforme a tabela a seguir.

Tabela 3: Detalhamento das unidades de ensino da disciplina de Fundamentos. Fonte: os autores.

\begin{tabular}{|c|c|}
\hline $\begin{array}{l}\text { Unidade } 1 \\
\text { Identificação } \\
\text { fenômenos a } \\
\text { estudados do } \\
\text { de vista das Ciências } \\
\text { da Natureza e } \\
\text { Matemática }\end{array}$ & $\begin{array}{l}\text { O Identificação de fenômenos presentes nos registros sobre os TCs; } \\
\text { o Exercício de busca de fontes secundárias sobre o contexto no qual o fenômeno está } \\
\text { situado; } \\
\text { o Decisão (a partir de critérios construídos coletivamente, considerando a vontade do } \\
\text { coletivo e os princípios do Movimento da Educação do Campo) sobre o fenômeno a } \\
\text { ser estudado; } \\
\text { o Identificação de sub-fenômenos relacionados ao fenômenos escolhidos a serem } \\
\text { estudados no tempo, no espaço e em diferentes escalas; } \\
\text { O Identificação de conceitos de Ciências da Natureza e Matemática relacionados aos } \\
\text { fenômenos. }\end{array}$ \\
\hline $\begin{array}{lr}\text { Unidade } 2 & - \\
\text { Planejamento } & \mathrm{e} \\
\text { desenvolvimento } & \text { de } \\
\text { Programa } & \text { de } \\
\text { Estudospor } & \\
\text { fenômenos } & \end{array}$ & $\begin{array}{l}\text { - Escolha e aprofundamento teórico de referenciais de base (livros, manuais etc.) das } \\
\text { Ciências da Natureza e Matemática; } \\
\text { ○ Escolha e aprofundamento teórico de referências técnico-científicas (artigos } \\
\text { científicos, dissertações e teses). }\end{array}$ \\
\hline $\begin{array}{l}\text { Unidade } \quad 3 \\
\text { Aprofundamentos } \\
\text { dos conceitos } \\
\text { estruturantes entre os } \\
\text { fenômenos } \\
\text { escolhidos }\end{array}$ & $\begin{array}{l}\text { o Situar os fenômenos na Escala Espacial; } \\
\text { o Situar os fenômenos na Escala Temporal; } \\
\text { o Situar os fenômenos quanto a Matéria Envolvida; } \\
\text { ○ Situar e desenvolver as explicações para as Transformações, Regularidades e } \\
\text { Energia envolvidos nos fenômenos; } \\
\text { o Regressão Linear e sua relação com os fenômenos; } \\
\text { o Geometria Espacial e sua relação com os fenômenos; } \\
\text { o Paisagem e sua relação com os fenômenos; } \\
\text { o Água e sua relação com os fenômenos; } \\
\text { o Plantas e Animais e sua relação com os fenômenos; } \\
\text { ○ Temperatura e sua relação com os fenômenos; } \\
\text { o Gases e sua relação com os fenômenos. }\end{array}$ \\
\hline
\end{tabular}

Fonte: Pesquisa dos autores. 
A construção coletiva do objetivo de estudo e dos critérios de escolha dos fenômenos a serem estudados condicionou a própria estruturação da componente curricular e a escolha de objetos de conhecimento mais consciente e pertinente ao contexto dos estudantes: seja o contexto do campo do qual eram oriundos e no qual realizavam o TC, seja o contexto do curso de licenciatura em Educação do Campo, como desdobramentos de uma política educacional específica, com princípios expressos em políticas de estado.

Nesse sentido, a menção aos princípios da Educação do Campo no décimo critério listado pelo grupo inicialmente não faz alusão somente aos princípios legais, segundo o Decreto 7.352 de novembro de 2010, mas também ao que os estudantes haviam estudados em outros componentes curriculares do curso, inclusive nas fases anteriores. De acordo com o segundo artigo do referido decreto, os princípios da Educação do Campo estariam ligados, dentre outros: ao respeito à diversidade; à formulação de projetos políticos pedagógicos específicos; ao desenvolvimento de políticas de formação de profissionais; à valorização da identidade das escolas do campo com base em conteúdos curriculares e metodologias adequadas à realidade dos sujeitos; a efetiva participação da comunidade e dos movimentos sociais do campo e à flexibilização da organização escolar com base nas atividades laborais do território; que significa considerar efetivamente à necessidades dos estudantes incluindo as condições climáticas e ciclos agrícolas, reconhecidos no referido decreto como condicionantes que não podem estar alheios à forma-conteúdo da escola do campo.

Assim, a compreensão profunda da dimensão natural de fenômenos como "geada", a "restituição da mata ciliar" e "a substituição da mata nativa por vasta plantação de Pinus" bem como a sua relação com a dinâmica social local, não apenas teriam relação com princípios da Educação do Campo, mas poderiam ser considerados para flexibilização e organização escolar que considerem profundamente as necessidades dos estudantes do campo envolvidos nesses fenômenos.

A seguir desenvolvemos o que chamamos de movimento centrífugo de relações com os conhecimentos específicos de Ciências da Natureza e Matemática o qual realizamos a partir dos fenômenos estudados.

\section{Conhecimentos das Ciências da Natureza e Matemática}

Passamos agora a uma sucinta descrição das ações a partir de cada uma 
das áreas de saber e dos fenômenos selecionados.

Em Matemática, com relação ao fenômeno "Substituição da Mata Nativa por vastas plantações de Pinus (Pinus sp.) em Timbó Grande, SC", trabalhamos com a comparação entre a rentabilidade da locação de terra para plantar Pinus e a rentabilidade com o uso da terra para produção de alimentos. A partir do trabalho de Sampaio (2015), no qual a autora compara a diferença da rentabilidade entre uma plantação de fumo e outra com diversidade de alimentos, o grupo pôde pesquisar os valores referentes às receitas e custos de diversas culturas e estabelecer seus próprios modelos, feitos a partir de funções polinomiais de grau 1. Com base nas cifras contidas em um contrato de arrendamento, $\mathrm{R} \$ \quad 60,00$ mensais por alqueire, os estudantes puderam fazer a comparação entre esses diferentes usos da terra e perceber a significativa diferença entre o valor pago pela locatária em um ano, e a rentabilidade da diversificação de um alqueire com alimentos, sendo esta, muito maior, desde que certos fatores sejam considerados constantes como a venda da produção.

O fenômeno "Ocorrência de geadas no Vale do Contestado, SC" foi estudado sob o conhecimento da Estatística, tomando como base o trabalho de Araujo et al. (2009), no qual os autores calcularam a probabilidade da ocorrência de geada com base na distribuição gama e dados coletados nas diversas estações meteorológicas do estado. Estudar este trabalho impôs desafios, visto que desconhecíamos o conceito estatístico supramencionado, o que exigiu seu estudo e seu redimensionamento aos estudantes, processo que após avaliação, mostrou que poderia ter sido mais eficiente. Por outro lado, o estudo deste fenômeno no contexto deste arranjo interdisciplinar pode exigir conhecimentos mais complexos, aspecto que mostra que os aprofundamentos em conhecimentos específicos podem ser feitos a partir deste tipo de proposta metodológica, problematizando o suposto esvaziamento de conteúdo, narrativa por vezes dirigida a propostas multi/interdisciplinares.

No caso da "Reconstituição da Mata Ciliar em São Pedro de Alcântara”, a análise da taxa de decrescimento de culturas permanentes no município nos anos de 2004 a 2014, contribuíram para compreender este processo de reconstituição da mata ciliar e foram feitos à luz do conceito de Regressão Linear, a partir do qual aprofundamos a análise com considerações que iam além dos fenômenos. Dos conhecimentos relacionados à Estatística, a Regressão 
Linear permite mobilizar um leque de aparatos conceituais ligados ao campo da Educação Matemática e da Matemática. Com efeito, diante das fórmulas dos coeficientes de regressão $\beta$ e $\alpha$ e $\mathrm{R}^{2}$, passase pelas operações de adição, subtração, multiplicação, divisão e potenciação. A representação matemática da regressão linear é uma função polinomial de grau 1, tema caro ao ensino de Matemática. Destarte, o ensino destas funções poderia ser feito à luz da regressão linear, inclusive dando mais sentido para os conceitos de domínio e imagem que, na regressão são restritos pelas séries. Diante dos dados colhidos para análise gráfica e posterior construção da regressão, esta ordem permite pensar sobre estes objetos a partir dos Registros de Representação Semiótica que sugere que o aprendizado das funções, por exemplo, ocorre quando os estudantes conseguem transitar pelos registros aritméticos, geométricos e algébricos deste conteúdo. Além disso, dados econômicos costumam ser constituídos de valores altos, o que praticamente inviabiliza encontrar os coeficientes fazendo os cálculos manualmente. Nesse sentido, os recursos computacionais auxiliam sobremaneira na tarefa de lidar com os dados e obter informações matemáticas capazes de auxiliar na compreensão dos fenômenos.

Figura 1: Regressão Linear - aspecto radial derivado dos estudos do componente curricular Matemática.

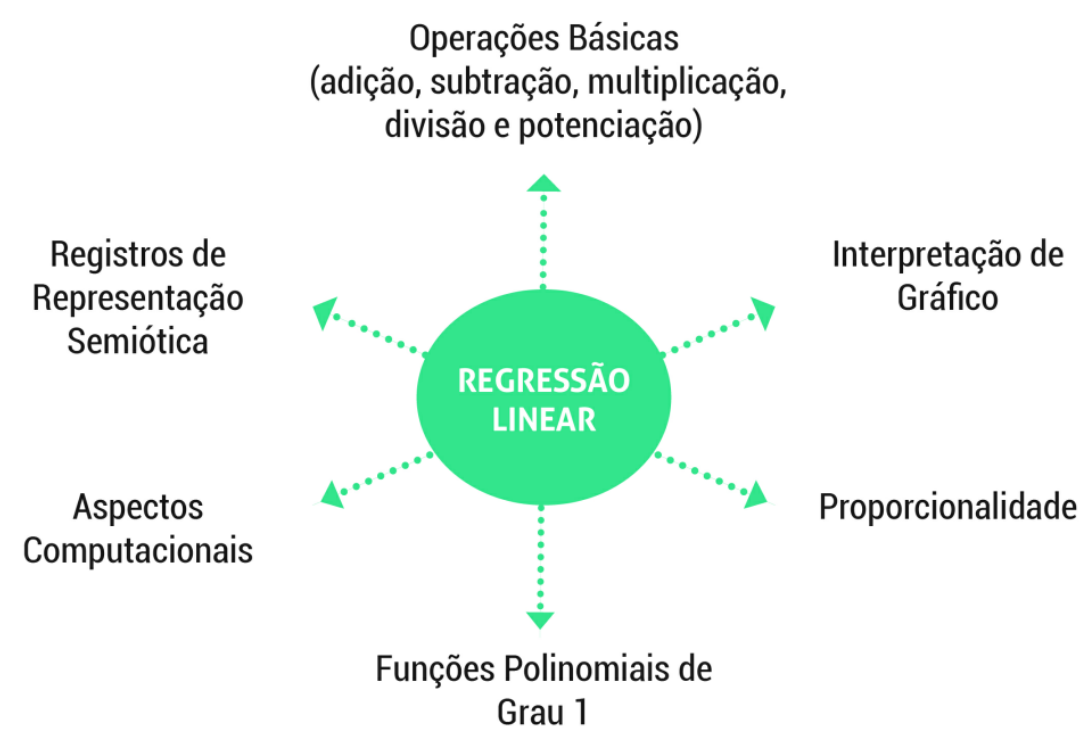

Fonte: Elaborada pelos autores.

Em relação à Biologia, um conjunto de conceitos oriundos da Ecologia de
Paisagem, Limnologia e Ecologia Aquática

e Fisiologia Vegetal foram acionados 
durante a realização dos programas de estudo. A escolha conceitual passou por um movimento de estudo preliminar dos fenômenos desde o ponto de vista disciplinar da Biologia. Assim, importou de fato estudar conceitos que ajudassem a compreender de forma evidente $\mathrm{o}$ fenômeno escolhido e que este pudesse entrar em diálogo com os próprios conhecimentos dos estudantes e dos outros sujeitos do território quando da realização do TC.

A título de exemplo, o caso da geada "Ocorrência de geadas no Vale do Contestado, SC", é bom para pensar sobre isso. Se por um lado os estudantes realizaram o movimento de estudo da água do ponto de vista físico-químico (polaridade, calor específico, coesão, força tênsil, tensão superficial, adesão) como elemento importante para compreensão do fenômeno, foi nos conceitos da fisiologia vegetal que eles puderam compor um texto de argumentação sobre os efeitos deste fenômeno da escala da planta até da agricultura em seu território (neste caso, no Vale do Contestado). Assim, eles estudaram transporte de água na planta, transcelular, transmembrana, simplasto, apoplasto, pressão de raiz e fluxo transpiratório. Foi com base nestes conceitos que eles foram capazes de tratar dos danos da geada e as táticas de sobrevivência das diferentes espécies de plantas. Para aprofundar essa compreensão sugerimos o acesso ao site criado pelos próprios estudantes da Educação do Campo: http://ledoct3.wixsite.com/ufsc ${ }^{\mathrm{iv}}$. Lá é possível encontrar o belo trabalho realizado por este grupo.

Em relação a "Reconstituição da Mata Ciliar em São Pedro de Alcântara" também operamos conceitualmente com a Ecologia de Paisagem (paisagem, escala, sucessão ecológica, efeito de borda), mas foi, sobretudo na limnologia e na ecologia aquática que encontramos base de aprofundamento para compreender os modos pelos quais a mata ciliar é um ecótono e tem função primordial não só para manutenção da qualidade das águas, mas também da biodiversidade terrestre e aquática. Daí nossas discussões seguiram para relação agricultura, usos da terra e áreas de preservação permanente (APPs).

$\mathrm{Na}$ mesma linha de discussão tratamos coletivamente da "Substituição da Mata Nativa por vastas plantações de Pinus (Pinus sp.) em Timbó Grande, SC". Nosso movimento de aprofundamento conceitual foi o de realizar uma inversão no enfoque de estudos. Chegamos à conclusão que para compreender a substituição da mata nativa local era preciso entender a matriz da paisagem original, ou seja, bioma Mata Atlântica, Floresta Estacional Semi- 
Decidual com presença marcante de Araucaria angustifolia (Pinheiro-doParaná). Foi a partir desta sequência que realizamos estudos da ecologia dessa espécie. Com base nesses estudos, discutimos o significado das

Figura 2: Malha conceitual estruturante dos fenômenos a partir dos estudos realizados no componente curricular Biologia.

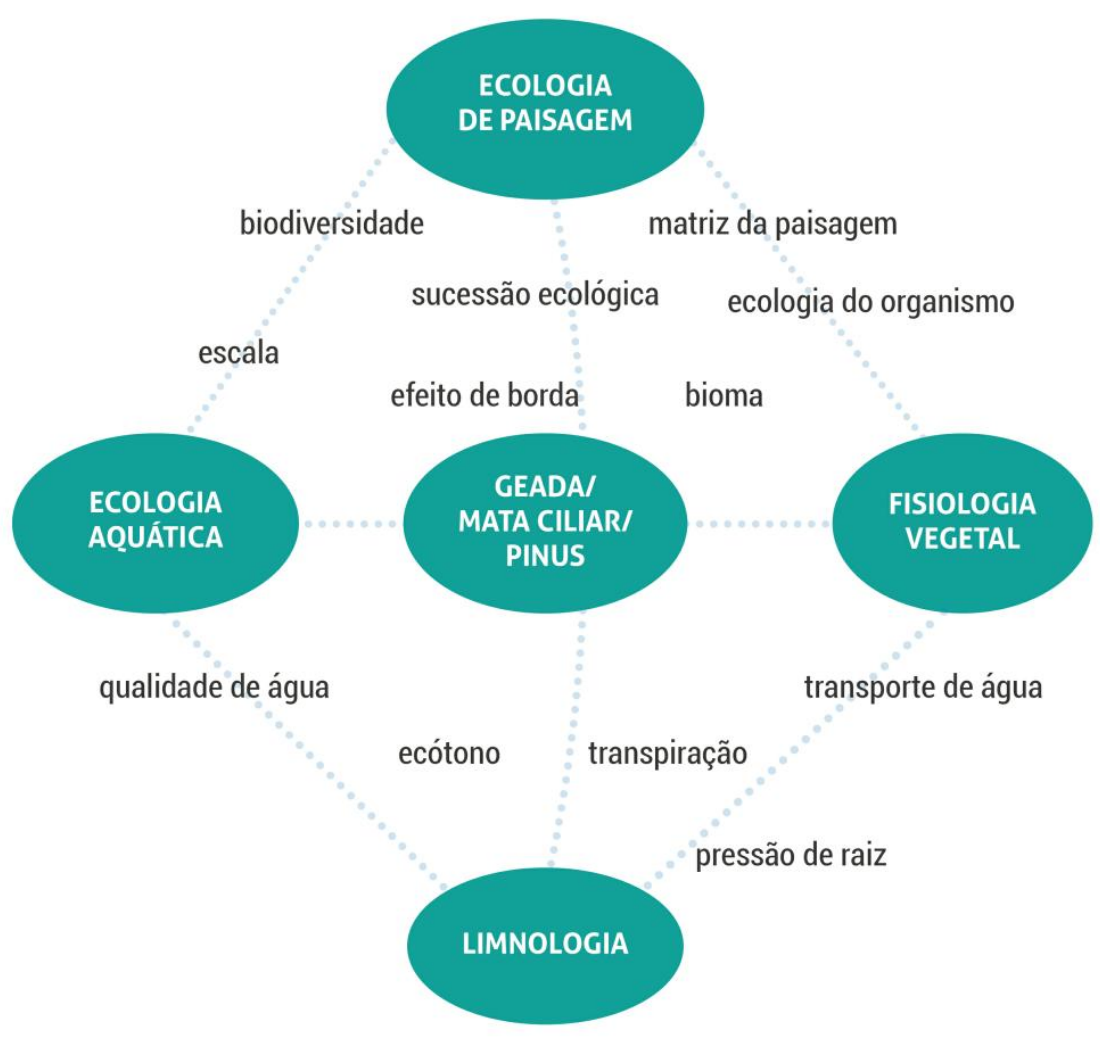

Fonte: Elaborada pelos autores.

Em relação à Física, a primeira aproximação com cada caso se deu a partir de referências que os próprios estudantes haviam indicado ou que havíamos encontrado buscando juntos. No caso da "Reconstituição da Mata Ciliar em São Pedro de Alcântara, SC", destacamos de Buss, Scheibe \& Furtado (2002) que houve "regeneração da cobertura florestal" transformações da paisagem para a região bem como os efeitos da monocultura do Pinus para biodiversidade e as comunidades do campo.

ECOLOGIA

E PAISAGEM 
temperaturas elevadas e altos índices pluviométricos, permitindo que em um tempo relativamente curto, como poucas dezenas de anos, as áreas abandonadas sejam recobertas por capoeiras e capoeirões, e atinjam até estágios de mata nativa secundária (Buss, Scheibe \& Furtado, 2002. p. 166, grifos nossos).

Desse aspecto pudemos destacar como que a temperatura é indicada ser uma variável importante no processo, o que está relacionado também com os altos índices pluviométricos e com as consequentes enchentes que, segundo o mesmo trabalho, são comuns nos meses de dezembro, janeiro e fevereiro, ou seja, na estação do ano verão. Mas como podemos explicar a ocorrência das estações do ano bem definida? Em todo o globo terrestre são perceptível as quatro estações de forma bem definida como em São Pedro de Alcântara? Qual relação dessa característica com a latitude e a exposição ao Sol? Como ocorrem as estações do ano? Como explicar a constância da inclinação do eixo de rotação da Terra em relação ao seu eixo de translação?

Outro trabalho identificado pelo grupo foi um estudo fenológico realizado no município de São Pedro de Alcântara, constituindo-se do monitoramento das fenofases reprodutivas de dezenove espécies botânicas durante mais de um ano. O estudo conclui que "as fenofases reprodutivas também são dependentes do ambiente onde se desenvolvem, razão pela qual muitas espécies apresentam períodos reprodutivos diferentes daqueles mencionados para outras regiões." (Mantovani et al. 2003, p. 451). Nesse sentido, segundo os autores, ainda nas conclusões do estudo, indicam que "em ambientes pouco sazonais, os fatores ambientais devem ter menor influência sobre as fenofases do que em ambientes notadamente sazonais. Sendo assim, a temperatura, o comprimento do dia e a pluviosidade correlacionam-se entre si, interferindo nas fenofases (Talora, 1996)" (Mantovani et al., 2003).

Além de reforçar o destaque anterior sobre a importância da temperatura, o trabalho traz gráficos com as medidas pluviométricas e de temperatura mensais, de onde foi possível estimar em aula a temperatura média de $20,3^{\circ} \mathrm{C}$ e uma variação de $25^{\circ} \mathrm{C}$ medida em janeiro e $16^{\circ} \mathrm{C}$ medida em julho. A menção à maior duração dos dias também é um aspecto relacionado com a sazonalidade, o que tem relação com a posição latitudinal do município, e pôde ser explicado também do ponto de vista geocêntrico com a ajuda da esfera armilar.

Em relação ao fenômeno "Substituição da Mata Nativa por vastas plantações de Pinus (Pinus sp.) em Timbó Grande, SC" buscou-se em um primeiro 
momento compreender as condições de ocorrência da mata nativa da região, composta por Mata de Araucária. Segundo Mattos (2011) a ocorrência natural da Araucaria angustifolia se dá em altitudes superiores a $400 \mathrm{~m}$, o que teria a ver com as condições climáticas propícias, pois a elevação das altitudes é inversamente proporcional às temperaturas médias e extremas (Mattos, 2011). "Encontra-se em uma vastíssima área de clima mesotermal do tipo C: clima temperado chuvoso, média de mês mais frio entre $18^{\circ} \mathrm{C} \mathrm{e}-3^{\circ} \mathrm{C} \mathrm{e}$ média do mês mais quente acima de 10 ${ }^{\circ}$ C." (Mattos, 2011, p.251-253). Por outro lado, em atividades de TC realizadas em Timbó-Grande, onde hoje a paisagem predominante é composta por florestas de Pínus, eram comuns relatos como: "O Pinus dá bem aqui.", “... a minha terra nunca deu nada ... só serve pra Pinus."

Sobre a "Ocorrência de geadas no Vale do Contestado, SC", dentre as causas destacadas por Pedrotti e Federova (2000) temos os anticiclones migratórios frios que provoca as baixas temperaturas também na região Sudeste do Brasil, mas, segundo os autores, as baixas temperaturas na região Sul do país "poderiam ser associados à advecção de ar frio de latitudes mais altas e a perda de energia pela radiação de ondas longas que são características de regiões de alta pressão com céu claro" (Pedrotti \& Fedorova, 2000, p. 2). Além das pistas iniciais sobre as condições climáticas para a ocorrência da geada, também se buscou estudar a tolerância ao frio, ou à aclimatação vegetal (Silva et. al., 2008) e os efeitos que os distintos tipos de geadas provocam nas plantas.

Como síntese, foram destacados com os estudantes, conforme figura 2, aspectos a serem aprofundados ao longo dos momentos de estudo em Física previstos para a Unidade III da componente curricular. Dentre esses aspectos foi considerado central o discernimento entre os conceitos de temperatura, calor e energia, cuja abordagem experimental realizada teve como inspiração o trabalho de Farias (2013) que fornece subsídios para superação de obstáculos epistemológicos à aprendizagem de termologia.

Figura 3: Calor, Frio e Temperatura - Mapa de referências e questões construído a partir dos estudos no componente curricular Física. 


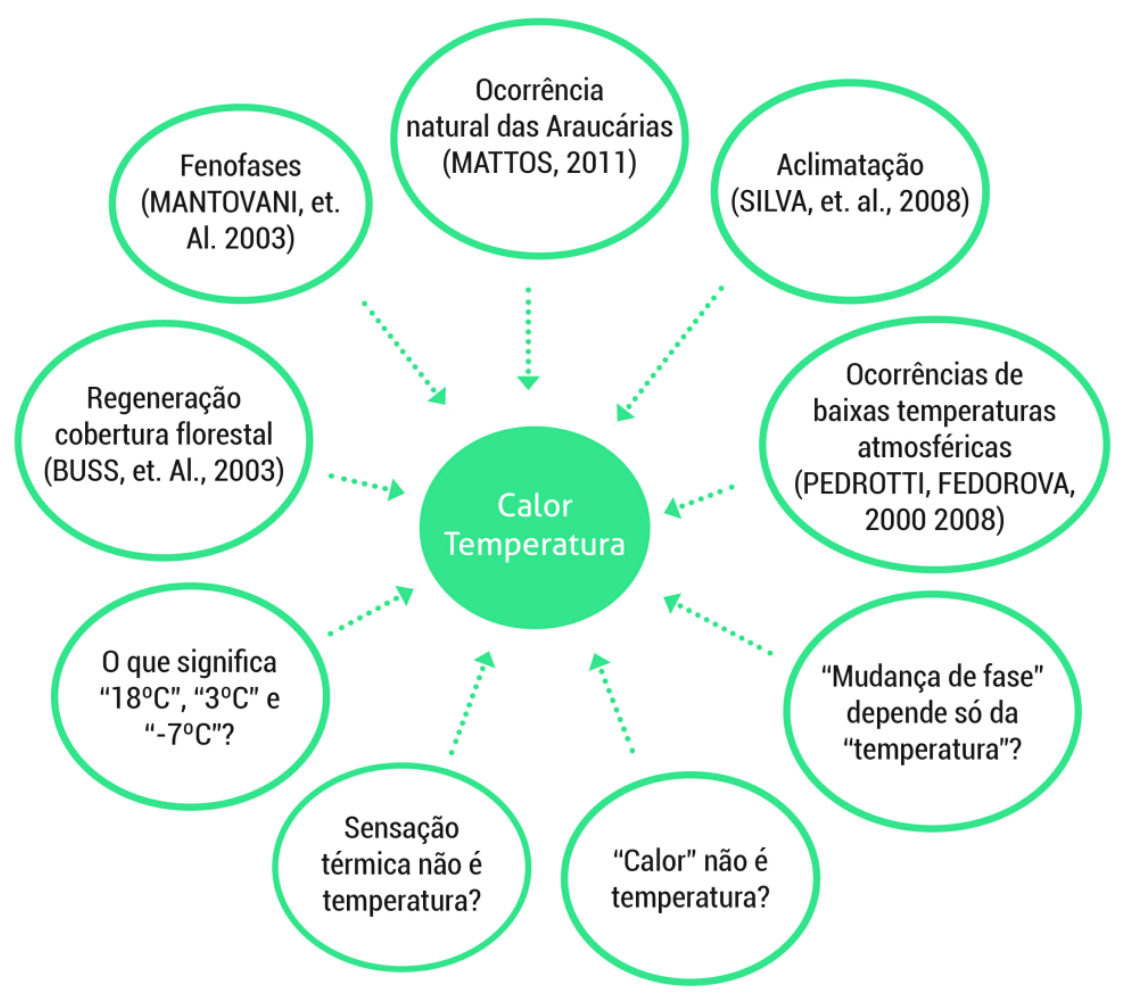

Fonte: Elaborada pelos autores.

\section{Considerações Finais}

As licenciaturas em Educação do Campo no Brasil têm oferecido desafios interessantes, dentre eles as estratégias para mobilizar potencialmente $\mathrm{o}$ conhecimento de diferentes componentes curriculares em uma organização por área de conhecimento. A jovialidade do curso e de sua modalidade permite e exige dos docentes o exercício de modos alternativos de organização de sua atuação docente.

Para operar com fenômenos no Ensino de Ciências da Natureza e Matemática na Educação do Campo estes não devem ser tratados como aqueles que estão fora do mundo material, isto é, aqueles sentidos e vividos desde o cotidiano das pessoas em seus mais diversos territórios. Ao dizer isso, defendemos que os fenômenos estão para além de qualquer movimento de naturalização do mundo e da natureza. Se por um lado, desde uma perspectiva fenomenológica, os fenômenos podem ser $a$ priori da consciência humana, é exatamente no texto (linguagem) das diferentes racionalidades e saberes que eles se materializam. Não haveria, deste modo, como pensar em fenômenos que não são a própria relação intrínseca entre matéria/discurso, matéria/linguagem do mundo. 
Dentre os desafios que esta proposta impõe encontra-se o curto período de tempo que temos para tratar de um amplo conjunto de conceitos e de preparar as aulas de conhecimento das Ciências da Natureza e Matemática, especialmente quando envolve conceitos não estudados anteriormente.

Ao mesmo tempo, a atividade de pesquisa na docência por parte dos professores se configura como uma possibilidade de didatizar conceitos mais complexos. Cabe destacar ainda que se por um lado a amplitude conceitual se torna limitada (quando comparada com aulas tradicionais, conduzidas de forma linear, progressiva) são os fenômenos que nos permitem de fato, estabelecer diálogos multi/interdisciplinares em direção aos fundamentos da área de conhecimento que se quer para a Educação do Campo. Destacamos o seu potencial enquanto mediador do mundo material (natureza) e da realidade dos diferentes modos de vida no campo, nas vivências em Ensino de Ciências da Natureza e Matemática nas licenciaturas em Educação do Campo.

Nossas reflexões consideram a natureza e a diversidade de possibilidades de organização das aprendizagens das Ciências da Natureza e da Matemática, sobretudo no contexto escolar do campo (da escola básica ao ensino superior).
Trabalhar com fenômenos é uma dentre outras possibilidades de organização da docência e do conhecimento nestes contextos. Nossas trajetórias individuais nos dizem que é nessa pluralidade que se sustenta a meta educativa de uma educação, que dê conta da complexidade da natureza, da vida humana e do papel da escola. Na licenciatura, forma é também conteúdo e, ao estabelecer esta consideração, fazemos o exercício de busca por não dicotomizar método e conhecimento científico, método de ensino e currículo.

\section{Referências}

Araujo, C. E. S., Massignam, A. M, Borges, R. C., \& Minuzzi, R. B. (2009). Previsão de geadas em Santa Catarina. Florianópolis, SC: Epagri.

Barad, K. (2007). Meeting the Universe Halfway: Quantum Physics and the Entanglement of Matter and Meaning. London, UK: Duke University Press.

Bourdieu, P. (2009). O senso prático. Petrópolis, RJ: Vozes.

Braidotti, R. (2006). Posthuman, All Too Human: Towards a New Process Ontology. Theory Culture Society, 23(7-8), 197-208. Doi:

https://doi.org/10.1177/026327640606923 $\underline{2}$ 
Bryant, L., Smicek, N., \& Harman, G. (2011). The Speculative Turn. Continental Materialism and Realism.

Burns, M. O., \& Smith, B. A. (2011). Editors' Introduction. Cosmos and History: The Journal of Natural and Social Philosophy, 7(1), 1-6.

Buss, M. D., Scheibe, L. F., \& Furtado, S. M. A. (2002). São Pedro de Alcântara: paisagem e rupturas. Geosul, 17(34), 155181. Doi: http://dx.doi.org/10.5007/\%25x

Castro, E. V. (2012). "Transformação" na antropologia, transformação da "antropologia". Mana, 18(1), 151-171. Doi: $\quad$ http://dx.doi.org/10.1590/S0104$\underline{93132012000100006}$

Coutinho, F. A., Goulart, M. I. M., Munford, D., \& Ribeiro, N. A. (2014). Seguindo uma lupa em uma aula de ciências para a educação infantil. Investigações em Ensino de Ciências, 19(2), 381-402.

Coutinho, F. A., Goulart, M. I. M., \& Pereira, A. F. (2017). Aprendendo a ser afetado: contribuições para a educação em ciências na educação infantil. Educação em Revista, $33 . \quad$ Doi: http://dx.doi.org/10.1590/0102$\underline{4698155748}$

Decreto n. 7.352. (2010, 04 de novembro). Dispõe sobre a política de educação do campo e o Programa Nacional de Educação na Reforma Agrária PRONERA. Recuperado de: http://portal.mec.gov.br/docman/marco2012-pdf/10199-8-decreto-7352-de4-denovembro-de-2010/file.

Farias, T. (2013). Atividades experimentais: contribuições para o aprendizado de calor e temperatura.
(Dissertação de Mestrado). Universidade Federal de Santa Catarina. Florianópolis.

Fenwick, T., \& Edwards, R. (2010). Actornetwork theory and education. London: Routledge.

Francis, C., Breland, T. A., Østergaard, E., Lieblein, G., \& Morse, S. (2013). Phenomenon-Based Learning in Agroecology: A Prerequisite for Transdisciplinarity and Responsible action. Agroecology and Sustainable Food Systems, 37(1), 60-75. Doi:

https://doi.org/10.1080/10440046.2012.71 $\underline{7905}$

Freitas, E., \& Palmer, A. (2016). How scientific concepts come to matter in early childhood curriculum: rethinking the concept of force. Cult Stud of Sci Educ, 11, 1201-1222.

Gutiérrez, J., \& Delgado, J. M. (1998). Teoría de la observación. In Delgado, J. M., Gutiérrez, J. (Orgs.). Método y técnicas cualitativas de investigación em ciências sociales (pp. 141-173.). Espanha: Sintesis.

Higgins, M. (2016). Decolonizing School Science: Pedagogically Enacting Agential Literacy and Ecologies of Relationships. In Tyalor, C. \& Hughes, C. (Eds). Posthuman Research Practices in Education (pp. 267-289). Basingstoke. UK: Palgrave Macmillam.

Kirsch, S. (2013). Cultural geography I: Materialist turns. Prog Hum Geogr, 37(3), 433-441.

Doi: https://doi.org/10.1177/030913251245947 $\underline{9}$ 
Lovino, S., \& Oppermann, S. (2012). Material Ecocriticism: Materiality, Agency, and Models of Narrativity. Ecozona, 3(1), 75-91.

Mantovani, M., Ruschel, A. R., Reis, M. S. dos, Puchalski, A., \& Nordari, R. O. (2003). Fenologia reprodutiva de espécies arbóreas em uma formação secundária da floresta atlântica. R. Árvore, 27(4), 451458. Doi: http://dx.doi.org/10.1590/S0100$\underline{67622003000400005}$

Mattos, J. R. (2011). O pinheiro brasileiro. Florianópolis, SC: Ed. da UFSC.

Merleau-Ponty, M. (2014). O Visível e o Invisível. São Paulo, SP: Perspectiva.

Ostergaard, E., Dahlin, B., \& Hugo, A. (2008). Doing phenomenology in science education: a research review. Studies in Science Education. 44(2), 93-121.

Pedrotti, C. B., \& Fedorova, N. (2000). Processos de formação de geada em pelotas no ano de 1996. Revista Brasileira de Meteorologia, 15(2), 1-19.

Quinn, J. (2013). Theorising learning and nature: post-human possibilities and problems. Gender and Education, 25(6), 738-753.

Doi: https://doi.org/10.1080/09540253.2013.83 $\underline{1811}$

Rautio, P. (2013). Children who carry stones in their pockets: on autotelic material practices in everyday life. Children's Geographies, 11(4), 394-408. Doi:

https://doi.org/10.1080/14733285.2013.81 $\underline{2278}$

Sampaio, D. M. (2015). Fragmentos de um exercício interdisciplinar: a Modelagem Matemática como mobilizadora do saber em uma experiência de estágio da Licenciatura em Educação do Campo.
Universidade Federal de Santa Catarina. Florianópolis.

Silva, E. P., Cunha, G. R., Pires, J. L. F., Dalmagro, G. A., \& Pasinato, A. (2008). Fatores abióticos envolvidos na tolerância de trigo à geada. Pesq. agropec. bras., 43(10), 1257-1265.

Doi: http://dx.doi.org/10.1590/S0100$\underline{204 X 2008001000002}$

Taguchi, H. L. (2010). Going beyond the theory/practice divide in early childhood education: introducing an intra-active pedagogy. New York, NY: Routledge.

UFSC. (2009). Projeto Político Pedagógica da Licenciatura em Educação do Campo - Área das Ciências da Natureza e Matemática. Florianópolis.

Whatmore, S. (2006). Materialist returns: practicing cultural geography in and for a more-than-human world. Cultural Geographies, 13(4), 600-609. Doi: https://doi.org/10.1191/1474474006cgj377 $\underline{o a}$

\footnotetext{
A virada ontológica - assim como as denominações virada cultural (século IX/XX) e virada linguística (século $\mathrm{XX}$ ) - tem sido o termo recorrente na filosofia e na antropologia (Viveiros de Castro, 2012) contemporâneas para se referir mais especificamente ao que autores de diferentes campos das Ciências Humanas têm chamado de virada não humana, virada material, virada póshumana ou virada especulativa (Whatmore, 2006; Braidotti, 2006; Burns \& Smith, 2011; Bryant et al., 2011; Kirsch, 2013). No âmbito internacional é possível encontrar movimentos com filiações distintas e especificidades, como, por exemplo, o Realismo Especulativo (Quentin Meillassoux), a Ontologia Orientada no Objeto (Graham Harman), o Materialismo Transcendental (Slavoj Žižek) e o Novo Materialismo (Rosi Braidotti, Manuel DeLanda). Há uma compreensão clara na filosofia e na antropologia de que a virada ontológica estaria se tornando um importante paradigma para as questões ambientais nas humanidades (Lovino \& Operman, 2012). Movimento semelhante já pode
} 
ser observado na educação e no Ensino das Ciências (Fenwick \& Edwards, 2010; Taguchi, 2010; Rautio, 2013; Quinn, 2013; Coutinho et. al., 2014; Coutinho, Goulart \& Pereira, 2017; Freitas \& Palmer, 2016).

ii Ementa: "Aprofundamento dos conceitos estudados na disciplina Fundamentos I e estabelecimento de aproximações metodológicas para a aprendizagem de conceitos das Ciências da Natureza e Matemática adequados às necessidades educativas do ensino fundamental" (UFSC, 2009).

iii No primeiro ano as atividades de TC são direcionadas ao território, levando em conta aspectos políticos, econômicos, sociais, ambientais, educacionais e de saúde. No segundo, os estudantes passam a realizar as atividades de TC com foco na escola. No terceiro e quarto anos, as atividades de TC são estruturadas pelas atividades de estágio (UFSC, 2009).

iv O site foi organizado pelos estudantes Antony Correa, Dara Ferreira e Daniel Bráz grupo responsável pelo estudo da "Ocorrência de geadas no Vale do Contestado, SC".

Recebido em: 30/07/2017

Aprovado em: 18/08/2017

Publicado em: 13/12/2017

\section{ORCID}

Marcelo Gules Borges

http://orcid.org/0000-0003-1231-2776

Juliano Espezim Soares Faria

http://orcid.org/0000-0002-0143-9790

Elizandro Maucrício Brick

iD http://orcid.org/0000-0002-6890-9566
Como citar este artigo / How to cite this article / Como citar este artículo:

APA:

Borges, M. G., Faria, J. E. S., \& Brick, E. M. (2017). Fenômenos como mediadores do processo educativo em Ciências da Natureza e Matemática na Educação do Campo. Rev. Bras. Educ. Camp., 2(3), 965-990. DOI: $\quad$ http://dx.doi.org/10.20873/uft.2525$\underline{4863.2017 \mathrm{v} 2 \mathrm{n} 3 \mathrm{p} 965}$

\section{ABNT:}

BORGES, M. G.; FARIA, J. E. S.; BRICK, E. M. Fenômenos como mediadores do processo educativo em Ciências da Natureza e Matemática na Educação do Campo. Rev. Bras. Educ. Camp., Tocantinópolis, v. 2, n. 3, p. 965-990, 2017. DOI: http://dx.doi.org/10.20873/uft.2525$\underline{4863.2017 \mathrm{v} 2 \mathrm{n} 3 \mathrm{p} 965}$ 